\title{
Preoperative Electroencephalographic Investigation in Frontal Lobe Epilepsy: Electroencephalographic and Electrocorticographic Recordings
}

\author{
L.F. Quesney
}

\begin{abstract}
The first section of this article deals with specific anatomic and pathophysiologic factors which contribute to a poor EEG localization of the interictal epileptic abnormality and to the unreliable seizure onset localization commonly reported in patients with frontal lobe epilepsy. The localizing effectiveness of long term EEG monitoring was reviewed in four different groups of frontal lobe epileptic patients who underwent preoperative EEG investigation with extracranial and intracranial electrodes. The results of this study reveal a continuum distribution of interictal epileptic disturbances, ranging from focal abnormalities to lobar or multi-lobar epileptogenesis. A frontal lobe localization of the seizure generator based on ictal recordings obtained with extracranial electrodes is rather poor and much more reliable results can be obtained by depth-electroencephalography.

RÉSUMÉ: Investigation EEG préopératoire dans l'épilepsie frontale: enregistrements EEG, SEEG et ECoG. La première partie de ce chapitre discute des facteurs anatomiques et pathophysiologiques qui sont à la base des difficultés rencontrées dans la localisation de l'activité épileptique interictale et dans la détection du point de départ des crises chez les patients avec épilepsie frontale. L'utilité du monitoring EEG prolongé en termes de localisation de l'activité épileptique a été évaluée chez quatre groupes de patients avec épilepsie frontale dont l'investigation préopératoire a été réalisée à l'aide d'électrodes extra et intracrâniennes. Notre étude révèle une grande variété d'anomalies allant des anomalies focales jusqu'aux anomalies épileptiques lobaires ou multi-lobaires. La localisation du point de départ intralobaire des crises d'épilepsie d'origine frontrale, basée sur des enregistrements réalisés avec électrodes extracrâniennes, est insatisfaisante. De biens meilleurs résultats peuvent être obtenus à l'aide d'électrodes implantées.
\end{abstract}

Can. J. Neurol. Sci. 1991; 18: 559-563

The ictal behavioral manifestations commonly reported in frontal lobe epilepsy are manifold and often they do not provide reliable localization of the site of seizure onset. ${ }^{1-6}$ Despite several attempts to correlate the clinical manifestations of frontal lobe epilepsy with anatomical sites involved at seizure onset and or spread, ${ }^{3.16}$ no consensus has been reached in terms of an ictal EEG-anatomo-clinical compartmentalization of the frontal lobe. The EEG localization of frontal lobe epiletogenic foci remains a challenge in spite of the increasing use of long term EEG-video monitoring technique during the presurgical investigation of patients with frontal lobe epilepsy. The poor localization of the interictal epileptic abnormality and the rather unreliable EEG localization of ictal onsets commonly reported in patients with frontal lobe epilepsy, ${ }^{2,3,18-23}$ is dependent upon some of the following factors:

- A small portion of the frontal lobe's anatomy is accessible to EEG recording with extracranial electrodes or with cortical leads, a situation which leads to an inherent risk of EEG sam- pling error when attempting to record EEG potentials generated in the frontal lobe's depth. The orbito-frontal cortex, the mesial interhemispheric convexity, the cingular cortex and to a similar extent the depth of the cerebral sulci within the frontal lobe $3,9,10,11,21,24,25$ are largely inaccessible to recording with extracranial electrodes. Small epileptogenic foci involving these anatomical structures, may be reflected as a widespread epileptic disturbance involving the fronto-centro-parietal or the frontocentro-temporal convexity, thus giving the false impression of a large epileptogenic zone. It is also a frequent finding that a small epileptic focus in the frontal lobe's depth may be undetected by extracranial electrodes. Even focal electrographic seizures involving for instance the cingular cortex may not be reflected in the surface EEG and some of these episodes could be associated with ictal behavioral manifestations, thus raising the suspicion of psychogenic attacks.

- A functional network of pathways permitting rapid seizure spread within and outside the frontal lobe, may in some cases

From the Montreal Neurological Institute and Hospital, Montreal

Reprint requests to: Dr. L.F. Quesney, Montreal Neurological Institute and Hospital, McGill University, 3801 University Street, Montreal, Quebec, Canada H3A 2B4 
account for a regional or even a multi-lobar distribution of the interictal spiking and of the ictal onsets, thus defying an accurate EEG localization. These pathways include the uncinate fasciculus, the cingulum ${ }^{26}$ and the arcuate fasciculus. Focal seizures may arise in a clinically silent region of the frontal lobe, producing ictal behavioral symptomatology only after seizure spread to nearing frontal or even central or temporal lobe structures. $^{3}$

- Secondary bilateral synchrony and secondary epileptogene$\operatorname{sis}^{8,12,22,24,27-29}$ may play a distinctive role in the genesis of bifrontal or generalized spike-and-wave activity which is so often observed in patients with unilateral frontal lobe epilepsy (see Table 1). Secondary bilateral synchrony is more likely to occur when the primary epileptic focus is located in the mesial parasagittal convexity, in the orbito-frontal cortex or in the cingular region. ${ }^{24,25,29}$ Bifrontal epileptogenesis could also be the result of a bilateral frontal lobe damage.

- Some of our recent findings indicate that the extent of the epileptogenic brain tissue in frontal lobe epilepsy, may range in size from relatively small epileptic foci to large epileptogenic zones, resembling a continuum distribution. ${ }^{21,23}$ One extreme of this continuum comprises rather small epileptogenic foci, as documented in patients who became and persisted seizure free after selective surgical removal of restricted frontal lobe regions. ${ }^{14}$ The distribution of interictal spiking in these patients is often widespread, even multilobar and seizure onsets are rarely localizable. The other extreme of this continuum includes patients with large epileptogenic zones, frequently involving several frontal gyri and at times, exhibiting a multi-lobar distribution. ${ }^{21}$ The epileptogenicity in patients with widespread epileptic zones is not uniform and it may often undergo focal accentuation in a given brain region. ${ }^{21,22,30}$ This may explain why patients portraying multi-lobar or extensive epileptogenic lesions may present with EEGs disclosing focal interictal spiking. It should be emphasized that even in the presence of a circumscribed frontal lobe focal pathological lesion, the distribution of ictal onsets and of the interictal spiking may be widespread. Thus lesions, are not necessarily accurate biological markers of the extent of epileptogenicity. ${ }^{33}$

This study intends to review the localizing effectiveness of long term EEG monitoring in four different groups of frontal lobe epileptic patients who underwent preoperative EEG investigation with extracranial and intracranial electrodes. In some groups the results of the preoperative EEG investigation will be correlated with the electrocorticography findings (ECoG).

\section{SubJeCts ANd Methods}

\section{Group A}

Includes 34 patients (mean age: 25.4 years) with frontal lobe epilepsy, who became and persisted seizure-free after restricted surgical removal of the anterior frontal region $(A F=18$ patients), the parasagittal convexity (PS $=10$ patients) or the frontal-opercular region ( $\mathrm{FO}=6$ patients). The post-surgical follow-up ranged from 2 to 46 years. The epileptogenic tissue responsible for the patients' habitual seizures was contained in the resected portion of the frontal lobe, and therefore this group represents a "pure culture" of the EEG and clinical manifestations of frontal lobe seizures originating in these regions. ${ }^{14} \mathrm{~A}$ more detailed report on these patients is available elsewhere. ${ }^{6}$

Ictal recordings were obtained in 9/32 patients of this series ( $\mathrm{AF}=4$ patients; $\mathrm{PS}=2$ patients; $\mathrm{FO}=3$ patients).

Electrocorticography (ECoG) was performed in 30/34 patients. All patients were operated on under local anesthesia and neurolepto-analgesia. Partial or total withdrawal of anticonvulsants was routinely performed, starting the night before surgery.

\section{Group B}

Comprises 22 patients (mean age: 23 years) presenting with poorly controlled complex partial seizures of frontal lobe origin who underwent preoperative long-term EEG monitoring. The distribution of the interictal and ictal findings in these patients is reported in further detail elsewhere. ${ }^{19}$

\section{Group C}

Consists of 12 patients with frontal lobe epilepsy (mean age: 27 years; range 15 to 46 years), in whom preoperative EEG investigation with extracranial electrodes failed to provide reliable localization of the anatomical substrate of seizure onset (see reference 33 for more details).

Chronic intracerebral and epidural electrodes were implanted in the frontal and temporal lobes either bilaterally (10 patients) or unilaterally ( 2 patients). The most common sites for depth electrode implantation in the frontal lobe included the orbitofrontal region, the fronto-cingular area and the supplementary motor cortex. Simultaneous depth electrode implantation was performed in the amygdala and hippocampus in all patients. Each depth electrode comprised 9 recording contacts separated at 5 millimeter intervals. Long term EEG-video monitoring utilizing a 16 channel computer assisted cable telemetry system ${ }^{31}$ was performed around the clock for a period of $2-4$ weeks.

\begin{tabular}{cccccccc}
\hline \multicolumn{6}{l}{ Table 1: Distribution of Interictal Spiking in Patients } & with Frontal Lobe Epilepsy \\
\hline \hline Group & Patients & F & L & ML & HS & BI & BS \\
\hline A & 34 & 3 & 14 & 2 & 4 & 0 & 16 \\
B & 22 & 3 & 12 & 4 & 0 & 1 & 0 \\
C & 12 & 6 & 4 & 4 & 0 & 5 & 6 \\
D & $\frac{45}{113}$ & $\underline{2}$ & $\underline{6}$ & $\underline{\mathbf{1 8}}$ & $\underline{6}$ & $\underline{4}$ & $\underline{20}$ \\
& 113 & $\mathbf{1 2}(32 \%)$ & $\mathbf{2 8}(24 \%)$ & $10(9 \%)$ & $10(9 \%)$ & $42(37 \%)$ \\
\hline
\end{tabular}

The distribution of the interictal epileptic abnormality obtained during extracranial EEG recordings or at electrocorticography was classified in the following categories: Focal (F), lobar (L), multilobar (ML), hemispheric (HS), bifrontal independent (BI) and bilaterally synchronous (BS). 


\section{Group D}

Comprises 45 children (median age 11 years, range 6 months to 15 years) who underwent preoperative EEG investigation and subsequent frontal lobe excisions at the Montreal Neurological Hospital between 1940 and 1980 (see references 22 and 23 for more details).

Patients belonging to groups $\mathrm{B}$ and $\mathrm{C}$ were submitted to preoperative long-term EEG-video monitoring utilizing a 16 channel cable telemetry system according to a technique described elsewhere. ${ }^{31,32}$ The main emphasis of the EEG investigation was placed in the localization of ictal onsets and in its correlation with the distribution of the interictal epileptic abnormality. The preoperative EEG investigation in patients belonging to groups $A$ and D consisted mostly of prolonged (2-4 hours) daytime EEG recordings with special extracranial electrodes. Seizures were recorded only in $9 / 34$ patients of group $A$ and in $21 / 45$ patients of group D.

The localization of the interictal epileptic abnormality obtained during extracranial EEG recordings and/or at electrocorticography was classified in the following anatomical categories:

Focal (F), lobar (L), multilobar (ML), hemispheric (HS), bifrontal independent (BI) or bilateral synchronous (BS) (see Tables 1, 2 and 3).

\section{Results}

\section{Distribution of the interictal spiking}

The anatomical distribution of the interictal epileptic abnormality in adult and pediatric patients with frontal lobe epilepsy is detailed in Table 1.

In the adult group, only a few patients belonging to group A presented with focal spiking $(3 / 34=9 \%)$. Fourteen patients belonging to this group exhibited lobar spiking (41\%). Multilobar or hemispheric spiking was recorded in $6 / 34$ patients (18\%). Sixteen patients (47\%) exhibited either bifrontal or generalized bilaterally synchronous interictal epileptic abnormality, most commonly of the spike-and slow wave type. A similar result was obtained in patients belonging to group B (Table 1) revealing a definite predominance for lobar spiking (12/22 patients $=55 \%$ ). It should be mentioned that generalized and bilaterally synchronous spike-and slow wave complexes were not included in the assessment of this group.

Patients belonging to group $\mathrm{C}$ presented with a more even distribution of the interictal spiking within the focal, lobar and multilobar categories.

The distribution of the interictal spiking in children with frontal lobe epilepsy is summarized in Table 1, D. Patients belonging to this group presented predominantly with multilobar spiking $(18 / 45$ patients $=40 \%)$. Only two patients $(4 \%)$ exhibited focal interictal epileptic activity in their EEGs. The incidence of bilateral synchrony was approximately the same as that observed in group $A$ of the adult population (Table 1). A good indicator of the localizing effectiveness provided by the interictal epileptic abnormality in frontal lobe epilepsy is available in the summary of Table 1, comprising 113 patients belonging to four different subgroups previously discussed. Only 14 of these patients $(12 \%)$ presented with focal interictal spiking. In contrast, 28 patients (24\%) exhibited multilobar epileptic discharges and the most prevalent interictal pattern consisted of bilateral synchronous epileptiform potentials, as documented in 42 patients $(37 \%)$.

\section{Electrocorticography Findings}

Electrocorticography was performed in 30 patients of group $A$, and in 42 patients of group D. The distribution of the cortical interictal spiking is summarized in Table 2. Patients in group A exhibited a predominantly regional distribution of the interictal spiking $(15 / 30=50 \%)$ whereas patients belonging to group $D$ exhibited predominantly a multilobar distribution of the interictal epileptic abnormality $(27 / 42$ patients $=64 \%)$.

\section{Seizure onset localization}

Seizures were recorded in $8 / 12$ patients of group $\mathrm{C}$ and in $21 / 45$ of group D. In approximately $50 \%$ of the patients $(14 / 29)$ the electrographic seizure onset could not be lateralized. Localized seizure onsets were more frequent in children $(8 / 21=38 \%)$ than in the population of frontal lobe patients who required preoperative EEG investigation with intracranial depth electrodes (C, $1 / 8$ patients $=12 \%$ ).

Depth electrode EEG investigation was carried out in the 12 patients belonging to group $\mathrm{C}$. Focal or regional seizure onset confined to one frontal lobe was observed in $9 / 12$ patients $(75 \%)$. A lateralized seizure onset was documented in $1 / 12$ patients. A bifrontal seizure onset without lateralization was recorded in $2 / 12$ patients.

Table 2: Cortical Distribution of Interictal Spiking in Frontal Lobe Epilepsy

\begin{tabular}{llllll}
\hline \hline & & F & Regional & L & ML \\
\hline A & 30 & 7 & 15 & 0 & 5 \\
D & $\frac{42}{72}$ & $\frac{2}{9}$ & $\frac{4}{19}(26 \%)$ & $\frac{9}{9}(12 \%)$ & $\frac{27}{32}$ \\
& & & & & \\
\hline
\end{tabular}

The distribution of the interictal epileptic abnormality obtained during extracranial EEG recordings or at electrocorticography was classified in the following categories: Focal (F), lobar (L), multilobar (ML), hemispheric (HS), bifrontal independent (BI) and bilaterally synchronous (BS).

Table 3: Localizing Effectiveness of Seizure Monitoring in Frontal Lobe Epilepsy

\begin{tabular}{lr}
\hline Seizures Recorded & 302 \\
Number of Patients & 16 \\
Localized Seizure Onset & 66 \\
$(22 \%)$ & 34 \\
$\begin{array}{l}\text { Lateralized Seizure Onset } \\
(11 \%)\end{array}$ & 111 \\
$\begin{array}{l}\text { Bilateral or Generalized Seizure Onset } \\
(37 \%)\end{array}$ & 57 \\
$\begin{array}{l}\text { Uninterpretable } \\
(19 \%)\end{array}$ & 34 \\
$\begin{array}{l}\text { Absence of Inctal EEG Changes } \\
(11 \%)\end{array}$ &
\end{tabular}

Reproduced with permission from Quesney and Gloor 1985. 
The effectiveness of long-term EEG monitoring in the localization/lateralization of seizure onsets in patients belonging to group B is illustrated in Table 3 . Only a minority of seizures recorded with extracranial electrodes exhibited a focal $(22 \%)$ or a lateralized $(11 \%)$ EEG onset. Bilateral or generalized seizure onset was the most frequent finding (37\%). Approximately $11 \%$ of frontal lobe seizures lacked correlation with ictal EEG changes.

\section{Discussion}

The anatomical distribution of the interictal spiking in frontal lobe epilepsy is not a reliable marker of the seizure generator. According to our study, only a minority of patients who became and remained seizure free after selective frontal lobe surgical removals, presented with focal interictal spiking in the frontal lobe during extracranial recordings or at electrocorticography. ${ }^{23}$ The predominant distribution of the interictal epileptic abnormality in this group of patients was widespread, involving the fronto-centro-temporal convexity. Entirely similar findings were observed in two additional groups of adult patients with frontal lobe epilepsy (groups B and C) ${ }^{19.33}$ The distribution of the interictal epileptic abnormality in children with frontal lobe epilepsy was predominantly multilobar as opposed to focal or regional and this appears to be an age-dependent phenomenon as reported elsewhere. ${ }^{22} \mathrm{~A}$ multilobar epileptogenesis was also the main finding at electrocorticography in these children.

In adults who became and persisted seizure free after restrictive surgical removal in the frontal lobe, the interictal ECoG findings were consistent with a more focal and/or regional distribution of the epileptic focus.

A frontal lobe localization of the seizure generator based on ictal recordings obtained with extracranial electrodes is rather poor in adult patients ${ }^{19.20}$ and somewhat better in children. ${ }^{22}$ Long-term EEG monitoring with intracranial electrodes is helpful in the localization of the seizure generator in patients with frontal lobe epilepsy, ${ }^{33}$ should the extracranial approach fail to achieve this goal.

Our findings confirm some of the EEG limitations in the localization of frontal lobe epileptic foci/zones mentioned earlier as an introductory remark. They also emphasize that despite a widespread distribution of the interictal epileptic foci, a more restricted ("critical mass") of epileptic brain tissue is required to produce the patient's habitual attacks. ${ }^{34}$ The extent of the frontal lobe surgical removal required to render the patient seizure free or significantly improved, must therefore be guided not only by the interictal and ictal EEG evidence, but also by the clinical seizure pattern, the results of neuro-imaging studies and the profile of the neuropsychological dysfunction. ${ }^{20.35-37}$

\section{REFERENCES}

1. Geier S, Bancaud J, Talairach J, et al. The seizures of frontal lobe epilepsy. Neurol 1977; 27: 951-958.

2. Quesney LF, Krieger C, Leitner C, et al. Frontal lobe epilepsy: clinical and electrographic presentation. In: Porter RJ, et al., eds. Advances in Epileptology: XVth Epilepsy International Symposium. New York: Raven Press 1984; 503-508.

3. Quesney LF. Seizures of frontal lobe origin. $I n$ : Pedley TA and Meldrum BS, eds. Recent Advances in Epilepsy - 3. Churchill Livingstone $1986 ; 81-110$.

4. Williamson PD, Wieser H-G, Delgado-Escueta AV. Clinical characteristics of partial seizures. In: Engel J Jr, ed. Surgical Treatment of the Epilepsies. New York: Raven Press 1987; 101-120.
5. Williamson PD, Spencer SS. Clinical and EEG features of complex partial seizures of extratemporal origin. Epilepsia 27 (Suppl 2): New York: Raven Press 1986; S46-S63.

6. Quesney LF, Constain M, Fish DR, et al. The clinical differentiation of seizures arising in the parasagittal and anterolateral dorsal frontal convexities. Arch Neurol 1990; 47: 677-679.

7. Ajmone-Marsan C, Goldhammer L. Clinical ictal patterns and electrographic data in cases of partial seizures of frontal-central-parietal origin. In: Brazier MAB, ed. Epilepsy, Its Phenomenon in Man. New York: Academic Press 1973; 235-258.

8. Goldring $\mathrm{S}$. The role of prefrontal cortex in grand mal convulsion. Arch Neurol 1972; 26: 109-119.

9. Ludwig BI, Ajmone-Marsan C, Van Buren J. Cerebral seizures of probable orbitofrontal origin. Epilepsia 1975; 16: 141-158.

10. Ludwig BI, Ajmone-Marsan C, Van Buren J. Depth and direct cortical recording in seizure disorders of extratemporal origin. Neurol 1976; 26: 1085-1099.

11. Mazars G. Criteria for identifying cingulate epilepsies. Epilepsia 1970; $41-47$

12. Pedley TA, Tharp BR, Herman K. Clinical and electroencephalographic characteristics of midline parasagittal foci. Ann Neurol 1981; 9: 142-149.

13. Commission on classification and terminology of the International League against Epilepsy. Proposal for revised classification of epilepsies and epileptic syndromes. Epilepsia 1989; 30: 389-399.

14. Rasmussen T. Characteristics of a pure culture of frontal lobe epilepsy. Epilepsia 1983; 24: 482-493.

15. Sutherling WW, Risinger MW, Crandall PH, et al. Focal functional anatomy of dorsolateral frontocentral seizures. Neurology 1990; 40: $87-98$.

16. Williamson PD, Spencer DD, Spencer SS, et al. Complex partial seizures of frontal lobe origin. Ann Neurol 1985; 18: 497-504.

17. Fegersten L, Roger A. Frontal epileptogenic foci and their clinical correlations. Electroenceph Clin Neurophysiol 1961; 13: 905913.

18. Quesney LF, Katsarkas A, Gloor P, et al. Contribution of naso-ethmoidal electrode recording in the electrographic exploration of frontal and temporal lobe epilepsy. In: Dam M, Gram L, Penry JK, eds. Advances in epileptology: XIIth Epilepsy International Symposium. New York: Raven Press 1981; 293-304.

19. Quesney LF, Gloor P. Localization of epileptic foci. In: Gotman J, Ives JR, Gloor P, eds. Long-term monitoring in epilepsy (EEG Suppl 37). Amsterdam: Elsevier Science Publishers BV 1985.

20. Quesney LF. Extracranial EEG evaluation. In: Engel J Jr, ed. Surgical treatment of the epilepsies. New York: Raven Press $1987 ; 129-166$.

21. Quesney LF, Olivier A. Pre-operative EEG evaluation in frontal lobe epilepsy. Acta Neurol Scand (Suppl 117) 1988; 78: 61-72.

22. Quesney LF, Fish DR, Rasmussen T. Extracranial EEG and electrocorticography in children with medically refractory partial seizures. J Epilepsy 1990 (in press).

23. Quesney LF, Constain M, Fish DR, et al. Frontal lobe epilepsy: A field of recent emphasis. Aset, lowa: Am EEG Technol 1990; 30: 177-193.

24. Ralston BL. Cingulate epilepsy and secondary bilateral synchrony. Electroenceph Clin Nerophysiol 1961; 13: 591-598.

25. Tharp BR. Orbital frontal seizures. An unique electroencephalographic and clinical syndrome. Epilepsia 1972; 13: 627-642.

26. Schneider RC, Crosby EC, Farhat SM. Extratemporal lesions triggering the temporal-lobe syndrome. J Neurosurg 1965; 22: 246263.

27. Morrell F. Secondary epileptogenesis in man. Arch Neurol 1985; 42: 318-335.

28. Morrell F. Varieties of human secondary epileptogenesis. J Clin Neurophyiol, New York: Raven Press 1989; 6(3): 227-275.

29. Tükel $\mathrm{K}$, Jasper $\mathrm{H}$. The electroencephalogram in parasagittal lesions. Electroencephalogr Clin Neurophysiol 1952; 4: 481-494.

30. Gloor P. Commentary: Approaches to localization of the epileptogenic lesion. In: Engel J Jr, ed. Surgical treatment of the epilepsies. New York: Raven Press 1987; 97-100.

31. Gotman J, Ives JR, Gloor P, et al. Monitoring at the Montreal Neurological Institute. In: Gotman J, Ives JR, Gloor P, eds. Long 
term monitoring in epilepsy (EEG Suppl 37). Amsterdam: Elsevier Science Publishers BV 1985; 327-340.

32. Gotman J. Automatic recognition of epileptic seizures in the EEG Electroencephalogr Clin Neurophysiol 1982; 54: 530-540.

33. Quesney LF, Constain M, Rasmussen T, et al. Pre-surgical EEG investigation in frontal lobe epilepsy. Proceedings of the Consensus Development Conference on Surgery for Epilepsy, March 19-21 NIH. Bethesda 1990 (in press).

34. Rasmussen T. Localizational aspects of epileptic seizure phenomena. In: Thompson RA, Green JR, eds. New perspectives in cerebral localization. New York: Raven Press 1982; 177-203.
35. Andermann FA. Identification of candidates for surgical treatment of epilepsy. In: Engel J Jr, ed. Surgical treatment of the epilepsies. New York: Raven Press 1987; 51-70.

36. Milner B. Psychological aspects of focal epilepsy and its neurosurgical management. In: Purpura DP, Penry JK, Walter RD, eds. Neurosurgical management of the epilepsies. Adv Neurol. New York: Raven Press 1975; 8: 299-332.

37. Sperling MR, Sutherling WW, Nuwer MR. New techniques for evaluating patients for epilepsy surgery. In: Engel J Jr, ed. Surgical Treatment of the Epilepsies. New York: Raven Press $1987 ; 235-257$. 